\title{
Shape memory behavior of Ti-rich Ti-Ni thin films formed by sputtering
}

\author{
A. Ishida, T. Sawaguchi and M. Sato
}

National Research Institute for Metals, 1-2-1 Sengen, Tsukuba, Ibaraki 305-0047, Japan

\begin{abstract}
The shape memory behavior of Ti-rich Ti-Ni thin films (Ti-45.2, 47.0, 47.9 at.\%Ni) annealed at 773, 823, 873K for $1 \mathrm{~h}$ was investigated. Transmission electron microscopy revealed that Ti-45.2at. \%Ni thin films contain randomly oriented $\mathrm{Ti}_{2} \mathrm{Ni}$ particles, while the other two films contain $\mathrm{Ti}_{2} \mathrm{Ni}$ precipitates with the same orientation as that of the TiNi matrix. In addition to the $\mathrm{Ti}_{2} \mathrm{Ni}$ precipitates, $\mathrm{GP}$ zones were also observed in a $\mathrm{Ti}-47.9 \mathrm{at}$. \% Ni thin film annealed at $773 \mathrm{~K}$ for $1 \mathrm{~h}$. Every specimen showed a two-stage transformation in a low stress range. The martensitic transformation temperature was found to decrease with increasing $\mathrm{Ti}$ content and decreasing annealing temperature. However, thin films containing GP zones showed significantly low transformation temperatures in spite of a low $T i$ content. The residual strain was found to increase with increasing $T i$ content and decreasing annealing temperature. The transformation strain was found to increase with decreasing Ti content and annealing temperature. In particular, the thin films containing GP zones showed a large transformation strain. The transformation temperatures of $\mathrm{Ti}$-rich $\mathrm{Ti}-\mathrm{Ni}$ thin films were generally higher than those of $\mathrm{Ni}$-rich $\mathrm{Ti}-\mathrm{Ni}$ thin films.
\end{abstract}

\section{INTRODUCTION}

Recently sputter-deposited thin films of $\mathrm{Ti}-\mathrm{Ni}$ are expected to be used as microactuators for micromachines such as micromanipulators and fluid microvalves[1-5]. In the past years, the present authors have been successful in quantitatively evaluating shape memory effect[6,7], stability of shape memory effect against thermal cycles[8], two way shape memory effect[9], superelasticity[10] and mechanical properties[11]. We found that the shape memory characteristics and mechanical properties of sputter-deposited $\mathrm{Ti}-\mathrm{Ni}$ thin films are comparable or even superior to those of bulk specimens[12]. Especially, it has been found that peculiar microstructures formed in Ti-rich Ti-Ni thin films[13] improve the shape memory characteristics[14] and mechanical properties[15]. In addition, it is known that the transformation temperatures of Ti-rich Ti-Ni thin films are higher than those in Ni-rich Ti-Ni films[16]. These findings have stimulated interests in Ti-rich $\mathrm{Ti}-\mathrm{Ni}$ thin films rather than Ni-rich Ti-Ni thin films from the viewpoint of both practical and fundamental aspects. The effect of heat treatment on the shape memory behavior of $\mathrm{Ti}-48.2$ at. \% Ni thin films has been already reported by the present authors[17], but the composition effect on the shape memory behavior has not been investigated systematically, though the composition effect on the transformation behavior has been reported by Gyobu et al.[16]. In this paper the effects of composition and heat treatment on the shape memory behavior of Ti-rich Ti-Ni thin films were investigated.

\section{EXPERIMENTAL}

Ti-rich Ti-Ni thin films of Ti-45.2, 47.0 and 47.9at. \%Ni were deposited on glass substrates with a carousel type magnetron sputtering apparatus shown in Fig. 1. In this study two targets of Ti and Ti-50at.\% Ni were used to control the film composition and the DC powers were controlled independently; the Ti target was varied from 305 to $420 \mathrm{~W}$ while the Ti-50at.\% Ni target was kept at $800 \mathrm{~W}$. The substrate temperature was $523 \mathrm{~K}$ and $\mathrm{Ar}$ gas pressure was $0.3 \mathrm{~Pa}$. The substrate holder was rotated at $60 \mathrm{rpm}$ to obtain composition homogeneity during sputtering. The deposition was carried out for $2 \mathrm{~h}$ and the film thickness ranged from 6 to $8 \mu \mathrm{m}$. 
The film composition was determined by EPMA analysis using two kinds of standard specimens, Ti-50at.\% $\mathrm{Ni}$ and Ti-51at. $\% \mathrm{Ni}$. After sputtering, they were removed from the glass substrates and then annealed at three different temperatures, 773,823 and $873 \mathrm{~K}$ for $1 \mathrm{~h}$ to produce crystallization. These heat treatments were carried out in a vacuum furnace equipped with infrared lamps. The microstructure of the films was observed with a transmission electron microscope. Thin foils for the transmission electron microscopy were prepared by double-jet electropolishing in an electrolytes consisting of $95 \%$ acetic acid and $5 \%$ perchloric acid by volume. The transmission electron microscopy studies were carried out at $423 \mathrm{~K}$ to avoid the formation of the martensitic phase and R-phase.

The shape memory behavior of the annealed films was measured with a small tensile tester equipped with an automatically controlled heater. The size of the sample used for this test was $0.4 \times 5 \mathrm{~mm}^{2}$ (gauge portion) and the thickness was from 6 to 8

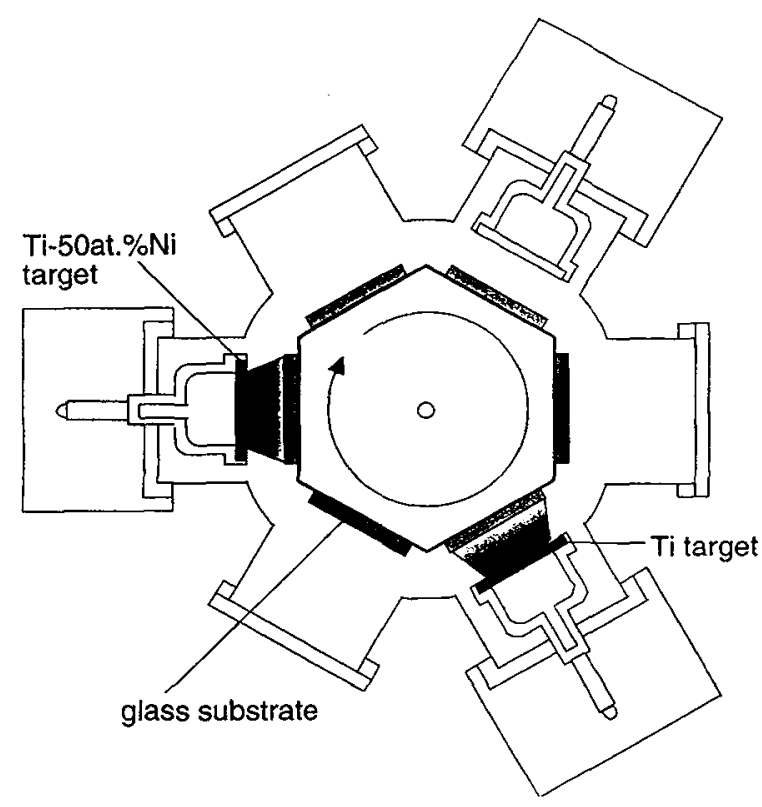

Fig.1 Schematic illustration of carousel type magnetron sputtering apparatus $\mu \mathrm{m}$. This test involved loading a sample at a high temperature, cooling it down to $143 \mathrm{~K}$ at a rate of $-10 \mathrm{Kmin}^{-1}$ and heating it back to the original temperature at a rate of $10 \mathrm{~K} \mathrm{~min}$ m $^{-1}$. A series of strain-temperature measurements under various constant stresses was carried out with one sample by varying the stress from 20 to $120 \mathrm{MPa}$ in steps of $20 \mathrm{MPa}$ and then from 120 to $600 \mathrm{MPa}$ in steps of $40 \mathrm{MPa}$. The transformation temperatures were obtained by the tangential method in the strain-temperature curves as described previously[17].

\section{RESULTS AND DISCUSSION}

\subsection{Microstructure}

The grain size in annealed thin films was not affected by heat treatment, but it decreased with increasing Ti content, being roughly $1 \mu \mathrm{m}$ for $\mathrm{Ti}-45.2 \mathrm{at} . \% \mathrm{Ni}, 3 \mu \mathrm{m}$ for $47.0 \mathrm{at} . \% \mathrm{Ni}$ and $5 \mu \mathrm{m}$ for $47.9 \mathrm{at} . \% \mathrm{Ni}$. Every film contains precipitates within the TiNi grains. Transmission electron microscopy revealed that $\mathrm{Ti}-45.2$ at. $\% \mathrm{Ni}$ thin films contain randomly oriented $\mathrm{Ti}_{2} \mathrm{Ni}$ particles[18], while the other films, Ti-47.0 and $47.9 \mathrm{at} \% \mathrm{Ni}$ thin films, contain $\mathrm{Ti}_{2} \mathrm{Ni}$ precipitates with the same orientation as that of the $\mathrm{TiNi}$ matrix[13]. In addition to the oriented $\mathrm{Ti}_{2} \mathrm{Ni}$, a Ti-47.9at.\% Ni thin film annealed at $773 \mathrm{~K}$ for $1 \mathrm{~h}$ shows G.P. zones[19]. These GP zones disappeared after annealing at $823 \mathrm{~K}$ for $\mathrm{Th}$ and only $\mathrm{Ti}_{2} \mathrm{Ni}$ precipitates remained in the films annealed at $823 \mathrm{~K}$ and $873 \mathrm{~K}$ [13]. The amount of $\mathrm{Ti}_{2} \mathrm{Ni}$ precipitates increases with increasing $\mathrm{Ti}$ content and their size increases with increasing annealing temperature. The $\mathrm{Ti}_{2} \mathrm{Ni}$ precipitates also tend to segregate at the grain boundaries with increasing annealing temperature[17].

\subsection{Shape memory behavior}

\subsubsection{Ti-45.2at.\%Ni thin film}

Fig. 2 shows the strain-temperature curves under various constant stresses of Ti- 45.2 at.\% Ni thin films annealed at 773,823 and $873 \mathrm{~K}$ for $1 \mathrm{~h}$. The thin film annealed at $773 \mathrm{~K}$ shows a two-stage elongation on cooling and a two-stage contraction on heating respectively[17]. The elongation on cooling is attributed to the R-phase transformation at a high temperature and the martensitic transformation at a low temperature, while the contraction on heating attributable to the reverse martensitic transformation at a 


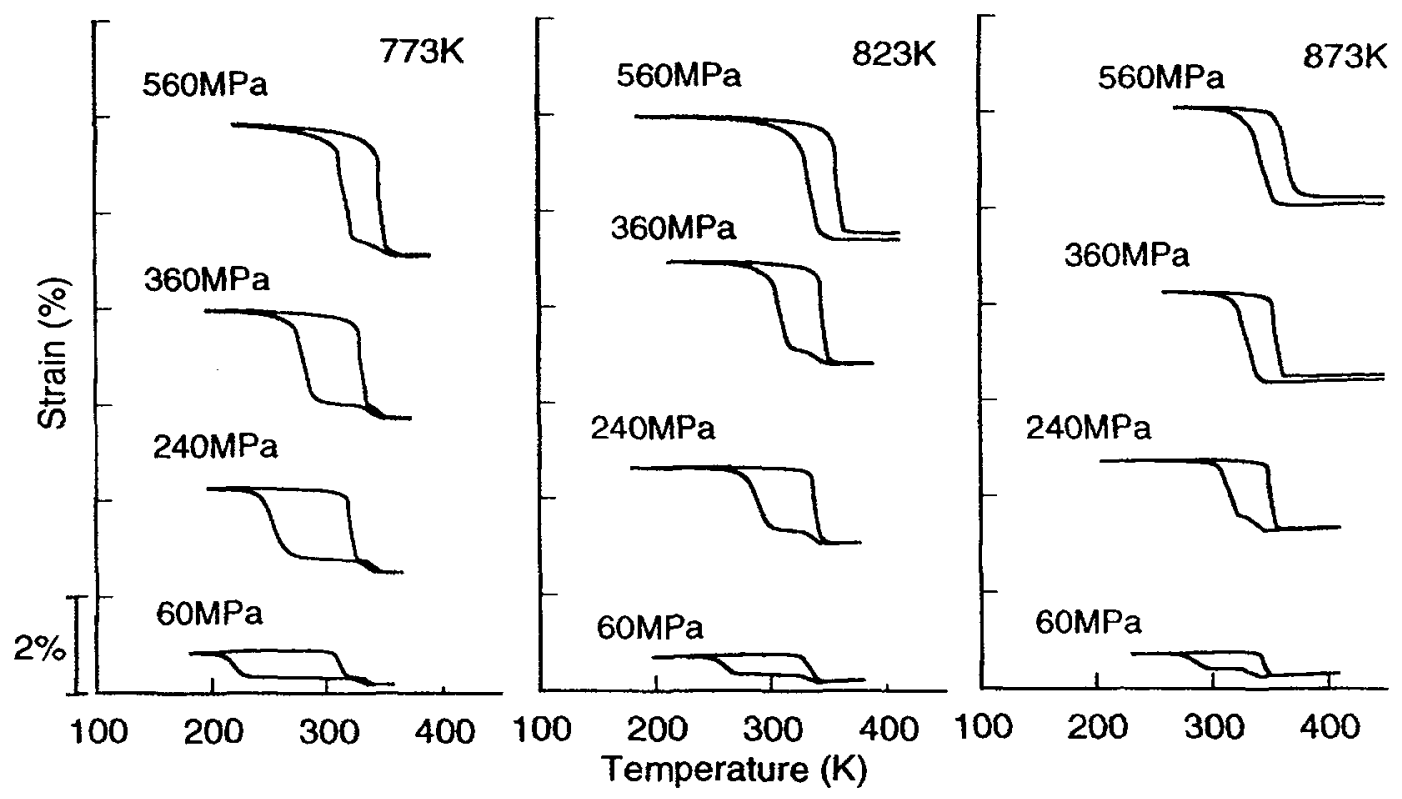

Fig. 2 Strain-temperature curves under various stresses of $\mathrm{Ti}-45.2 \mathrm{at} . \% \mathrm{Ni}$ thin films annealed at $773 \mathrm{~K}, 823 \mathrm{~K}$ and $873 \mathrm{~K}$ for $1 \mathrm{~h}$

low temperature and the reverse R-phase transformation at a high temperature. The temperature for each transformation increases with increasing stress. For example, the martensitic transformation start temperature(Ms) increases considerably from $209 \mathrm{~K}$ at $60 \mathrm{MPa}$ to $310 \mathrm{~K}$ at $560 \mathrm{MPa}$, while the $\mathrm{R}$ phase transformation start temperature(Rs) slightly increases from $336 \mathrm{~K}$ at $60 \mathrm{MPa}$ to $357 \mathrm{~K}$ at $560 \mathrm{MPa}$. Since the martensitic transformation temperature has stronger dependence on stress than the reverse martensitic transformation temperature, the temperature hysteresis decreases with increasing stress. The strain caused by the forward transformations recovered by the reverse transformations completely for the thin film annealed at $773 \mathrm{~K}$. The transformation strain was $2.8 \%$ at $560 \mathrm{MPa}$, being a little small compared with those of Ti-47.0at.\% Ni and-47.9at.\% Ni films. These shape memory characteristics of the Ti-45.2at.\% Ni thin film annealed at $773 \mathrm{~K}$ for $1 \mathrm{~h}$ can be explained by the existence of fine $\mathrm{Ti}_{2} \mathrm{Ni}$ particles as follows. The fine $\mathrm{Ti}_{2} \mathrm{Ni}$ particles in the thin film annealed at $773 \mathrm{~K}$ are considered to resist the deformation accompanied with the martensitic transformation and thus reduce the transformation temperature. They also suppress a plastic deformation associated with the transformation and the preferential orientation of the martensite variants, resulting in a small residual strain and a small transformation strain. Annealing at high temperatures of 823 and $873 \mathrm{~K}$ raises the martensitic transformation temperature. This increase in the martensitic transformation temperature results from the coarsening and grain boundary segregation of the $\mathrm{Ti}_{2} \mathrm{Ni}$ particles. When the martensitic transformation temperature is high like in the thin films annealed at $823 \mathrm{~K}$ and $873 \mathrm{~K}$, the two-stage contraction cannot be seen in the heating curve and a single-stage contraction due to the reverse martensitic transformation alone appears instead. Furthermore, at high stresses (560MPa for the $823 \mathrm{~K}$ annealing, 360MPa for the $873 \mathrm{~K}$ annealing) a single-stage elongation due to the martensitic transformation occurs instead of the two-stage elongation. Annealing at $873 \mathrm{~K}$ reduces the transformation strain from $2.76 \%$ for $773 \mathrm{~K}$ to $2.01 \%$ for $873 \mathrm{~K}$ and increases the residual strain. The decrease in the transformation strain and the increase in the residual strain are ascribed to the coarsening and grain boundary segregation of the $\mathrm{Ti}_{2} \mathrm{Ni}$ particles.

\subsubsection{Ti-47.0at.\% Ni thin films}

Fig. 3 shows the strain-temperature curves under various constant stresses of Ti-47.0at.\%Ni thin films annealed at 773,823 and $873 \mathrm{~K}$ for $1 \mathrm{~h}$. It was found that, compared with the shape memory behavior of 


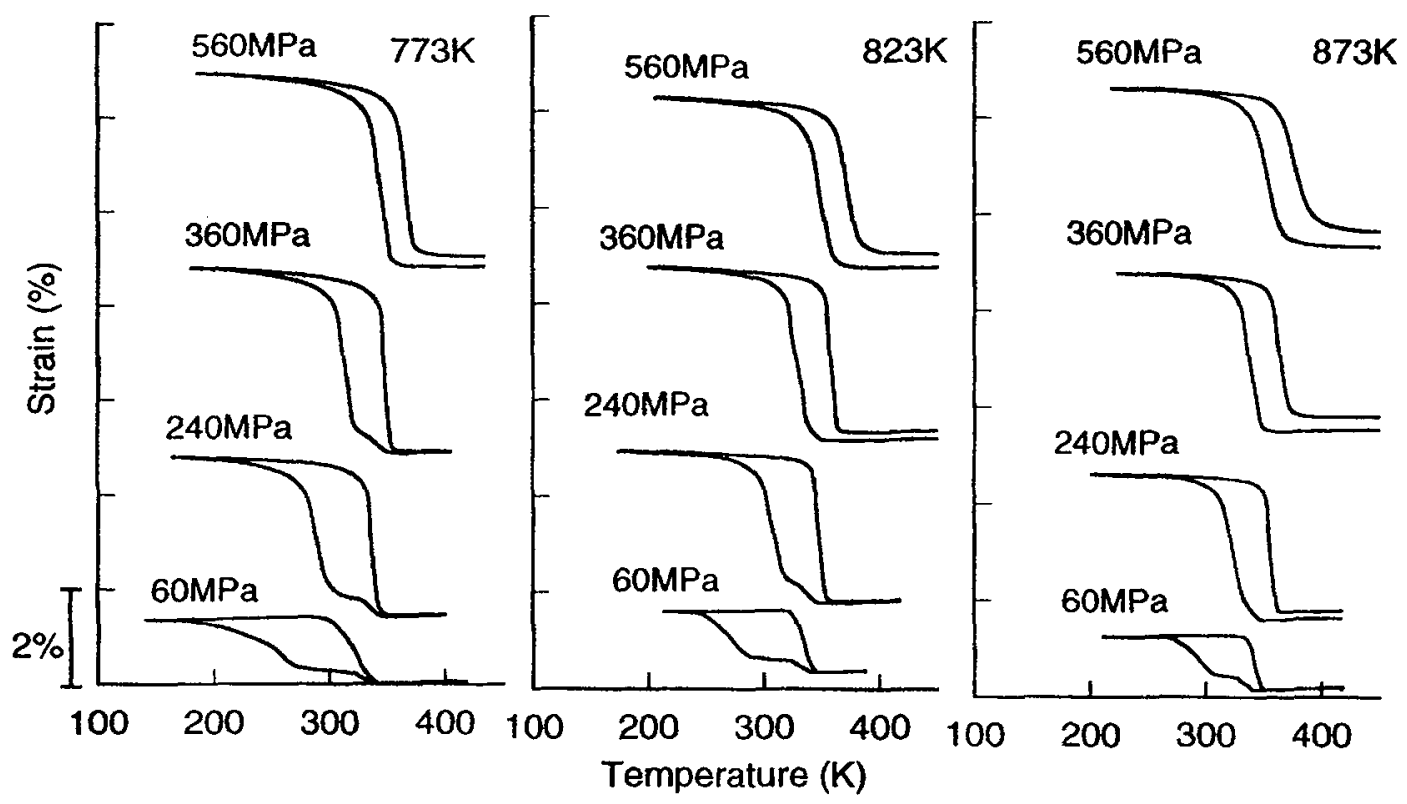

Fig. 3 Strain-temperature curves under various stresses of $\mathrm{Ti}-47.0 \mathrm{at} . \% \mathrm{Ni}$ thin films annealed at $773 \mathrm{~K}, 823 \mathrm{~K}$ and $873 \mathrm{~K}$ for $1 \mathrm{~h}$

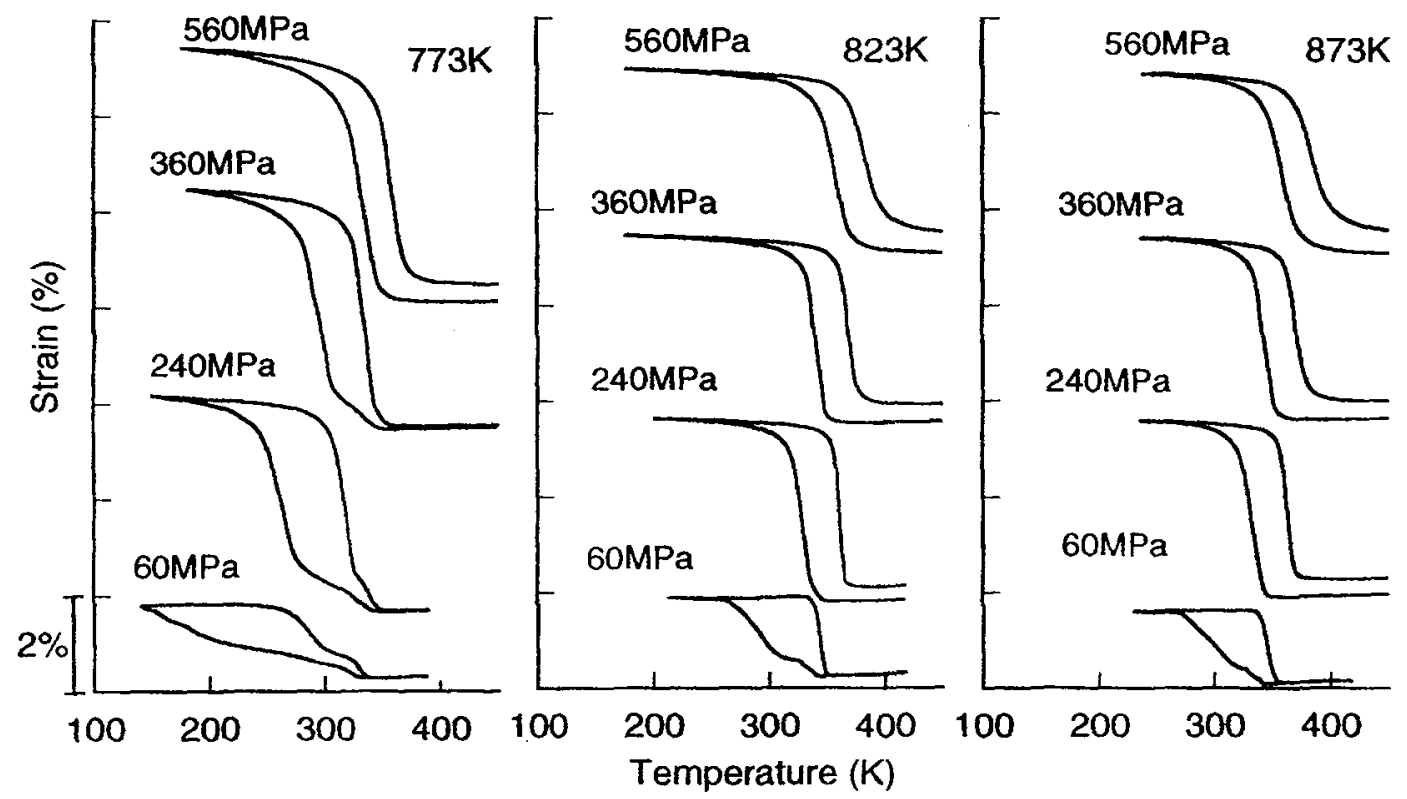

Fig. 4 Strain-temperature curves under various stresses of Ti-47.9at.\%Ni thin films annealed at $773 \mathrm{~K}, 823 \mathrm{~K}$ and $873 \mathrm{~K}$ for $1 \mathrm{~h}$ 
the Ti-45.2at.\% Ni thin films, the transformation temperatures are high and the transformation strains and residual strains are large. This comes from a smaller amount of $\mathrm{Ti}_{2} \mathrm{Ni}$ precipitates and larger grain size. Like in the Ti-45.2at.\% Ni thin films, the Ms temperature increases with increasing annealing temperature. The transformation strain at $560 \mathrm{MPa}$ decreases with increasing annealing temperature. Further, the residual strain appears at $560 \mathrm{MPa}$ for $773 \mathrm{~K}$ annealing and at $360 \mathrm{MPa}$ for $823 \mathrm{~K}$ annealing and at $240 \mathrm{MPa}$ for $873 \mathrm{~K}$ annealing respectively. Apparently the coarsening and grain boundary segregation of $\mathrm{Ti}_{2} \mathrm{Ni}$ precipitates are responsible for the degradation in the shape memory effect.

\subsubsection{Ti-47.9at.\%Ni thin films}

Fig. 4 shows the strain-temperature curves under various constant stresses of Ti-47.9at.\% Ni thin films annealed at 773,823 and $873 \mathrm{~K}$ for $1 \mathrm{~h}$. The interesting thing in this figure is the shape memory behavior of the thin film annealed at $773 \mathrm{~K}$ for $1 \mathrm{~h}$. The transformation temperatures of this film are significantly lower than those of Ti-47.0at.\% Ni thin films in spite of less Ti. Besides the plastic strain is small though the transformation strain is considerably larger than those of Ti-47.0at.\%Ni thin films. This peculiar shape memory behavior comes from the existence of GP zones. The strain field formed around the GP zones suppresses the deformation associated with the transformation, thus resulting in low martensitic transformation temperatures. The same strain field also suppresses the movement of dislocations while the reorientation of variants, i.e. the movement of twin boundary, is easy since the lattice is continuous. As shown in the figure, the disappearance of GP zones after annealing at $823 \mathrm{~K}$ increases the residual strain and the martensitic transformation temperature, and decreases the transformation strain drastically. In addition to the existence of GP zones, he composition of the matrix may affect the transformation temperatures in the film annealed at $773 \mathrm{~K}$ since the matrix in the film is likely to be supersaturated in Ti. However, the effect of the matrix composition is not clear for Ti-rich composition[12] and hence it cannot be discussed in detail.

\subsubsection{Composition dependence of transformation temperature}

Fig. 5 shows the composition dependence of the martensitic transformation start temperature. For the films annealed at 823 and $873 \mathrm{~K}$, the martensitic transformation start temperature decreases with increasing $\mathrm{Ti}$ content. This is due to an increase of the $\mathrm{Ti}_{2} \mathrm{Ni}$ amount. However, a $\mathrm{Ti}-47.9 \mathrm{at} . \% \mathrm{Ni}$ thin film annealed at $773 \mathrm{~K}$ for $1 \mathrm{~h}$ shows a lower martensitic transformation temperature than a Ti-47.0at.\% Ni thin film annealed at the same temperature in spite of the small amount of $\mathrm{Ti}_{2} \mathrm{Ni}$. This decrease in the martensitic transformation start temperature can be explained by the existence of GP zones as discussed in the previous section. The reverse martensitic transformation temperature was also found to show similar dependence on the composition and

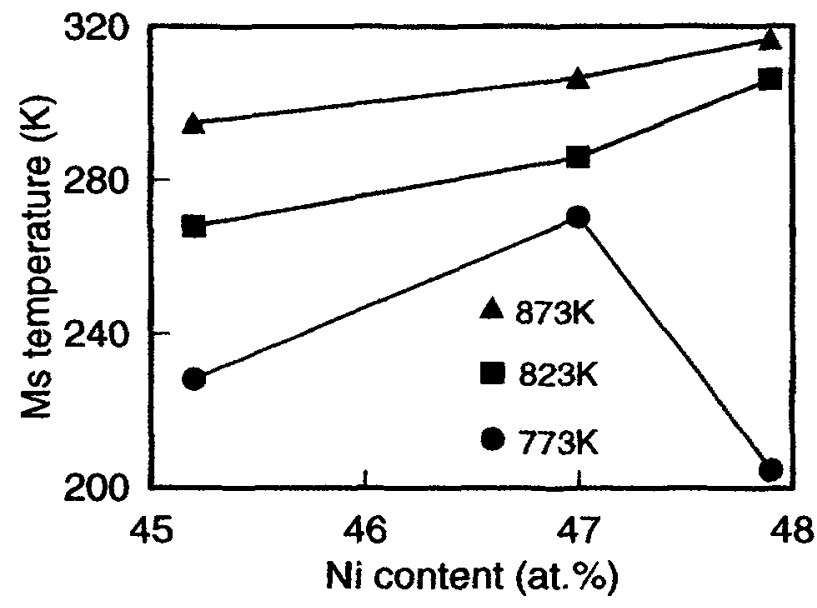

Fig.5 Composition dependence of the martensitic transformation start temperature(Ms) of Ti-rich Ti-Ni thin films annealed at $773 \mathrm{~K}, 823 \mathrm{~K}$ and $873 \mathrm{~K}$ annealing temperature, but the effect is small compared with the martensitic transformation temperature. The thermal hysteresis, therefore, decreases with increasing annealing temperature and $\mathrm{Ni}$ content. In contrast to the martensitic transformation temperatures, the $\mathrm{R}$ phase transformation temperatures of annealed thin films are almost constant except for a Ti-47.9at.\%Ni thin film with GP zones, which shows a low R-phase transformation temperature. The fact that Ti-rich Ti-Ni thin films show relatively high $\mathrm{R}$-phase transformation temperatures (approximately $340 \mathrm{~K}$ for the R-phase transformation start temperature) irrespective of composition and annealing conditions seems favorable for the practical use. 


\section{CONCLUSION}

Ti-rich Ti-Ni thin films of Ti-45.2at.\%, 47.0at.\%Ni and 47.9at.\%Ni were annealed at 773,823 and $873 \mathrm{~K}$ and their shape memory behaviors were investigated. The obtained results were as follows.

(1) The martensitic transformation temperature of thin films with $\mathrm{Ti}_{2} \mathrm{Ni}$ precipitates alone decreases with increasing Ti content and decreasing annealing temperature, but a Ti-47.9at.\% Ni film annealed at $773 \mathrm{~K}$ for $1 \mathrm{~h}$ shows a low martensitic transformation temperature owing to the existence of GP zones.

(2) The R-phase transformation temperatures of thin films with $\mathrm{Ti}_{2} \mathrm{Ni}$ precipitates alone are almost constant, but it is low in a Ti-47.9at.\% Ni film with GP zones.

(3) The residual strain decreases with decreasing Ti content and increasing annealing temperature, but a thin film annealed at $773 \mathrm{~K}$ for $1 \mathrm{~h}$ shows a small residual strain owing to the existence of GP zones.

(4) The transformation strain increases with decreasing Ti content and decreasing annealing temperature. Especially , a Ti-47.9at.\% Ni film with GP zones shows a large transformation strain.

\section{References}

1. A.D.Johnson, J. Micromech. Microeng 1, 34(1991).

2. M. Kohl, D. Dittmann, E. Quandt, B.Winzek, S. Miyazaki and D.M. Allen, Mater. Sci. Eng. A273-275, 784(1999).

3. D.S. Grummon, Li Hou, Z. Zhao and T. J. Pence, J de Physique IV, C8-665(1995).

4. S. Miyazaki and A. Ishida, Mater. Sci. Eng. A273-275, 106(1999).

5. T. Lehnert, S. Tixier, P. Boni and R. Gotthardt, Mater. Sci. and Eng. A273-275, 713(1999).

6. A.Ishida,A.Takei and S.Miyazaki, Thin Solid Films 228, 210(1993).

7. A.Ishida,M.Sato,A.Takei,K.Nomura and S.Miyazaki, Metall.Mater.Trans.A 27A, 3753(1996).

8. K. Nomura, S. Miyazaki and A. Ishida, Proc. 5th Int. Conf. on New Actuators(ACTUATOR-96),

Bremen, Germany, p.417(1996).

9. M.Sato,A.Ishida and S.Miyazaki, Thin Solid Films 315, 305(1998).

10. A.Ishida,A.Takei,M.Sato and S.Miyazaki, Thin Solid Films 281-282, 337(1996).

11. A.Ishida,M.Sato,S.Miyazaki, Phil. Mag. A 80, 967(2000).

12. A.Ishida and S.Miyazaki, Transaction of the ASME 121, 2(1999).

13. A.Ishida,K.Ogawa,M.Sato and S.Miyazaki, Metall. Mater.Trans.A 28A, 1985(1997).

14. S.Kajiwara,T.Kikuchi ,K.Ogawa,T.Matsunaga and S.Miyazaki : Phil. Mag. Lett. 74, 137(1996).

15. A. Ishida, M. Sato and S. Miyazaki, Mater. Sci. Eng. A273-275, 754(1999).

16. A.Gyubu,Y.Kawamura,H.Horikawa and T.Saburi, Mater.Trans.JIM 37, 697(1996).

17. A.Ishida,M.Sato,A.Takei and S.Miyazaki, Mater.Trans.,JIM 36, 1349(1995).

18. Y.Kawamura,A.Gyobu,H.Horikawa and T.Saburi, Journal de Physique IV, C8-683(1995).

19. Y.Nakata,T.Tadaki,H.Sakamoto,A.Tanaka and K.Shimizu, Journal de Physique IV, C8-671(1995). 